\title{
Abdomen Agudo una revisión de las teorías
}

Hernán Pérez Montesinos Luis Pérez Montesinos 



\section{Abdomen Agudo una revisión de las teorías}


Hernán Pérez Montesinos

Luis Pérez Montesinos 
Abdomen Agudo una revisión de las teorías

(C) Hernán Pérez Montesinos

Luis Pérez Montesinos

2021,

Publicado por acuerdo con los autores.

(C) 2021, Editorial Grupo Compás

Guayaquil-Ecuador

Grupo Compás apoya la protección del copyright, cada uno de sus textos han sido sometido a un proceso de evaluación por pares externos con base en la normativa del editorial.

El copyright estimula la creatividad, defiende la diversidad en el ámbito de las ideas y el conocimiento, promueve la libre expresión y favorece una cultura viva. Quedan rigurosamente prohibidas, bajo las sanciones en las leyes, la producción o almacenamiento total o parcial de la presente publicación, incluyendo el diseño de la portada, así como la transmisión de la misma por cualquiera de sus medios, tanto si es electrónico, como químico, mecánico, óptico, de grabación o bien de fotocopia, sin la autorización de los titulares del copyright.

Editado en Guayaquil - Ecuador

ISBN 978-9942-33-372-8

DOI. https://doi.org/10.37959/se.voio.167

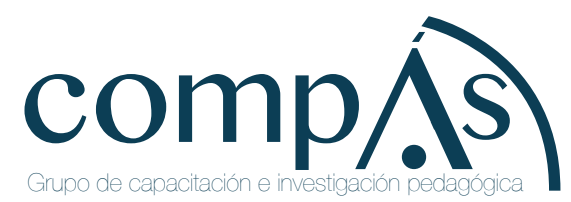


Cita.

Pérez, H., Pérez, L., (2021). Abdomen Agudo una revisión de las teorías. Editorial Grupo Compás. 


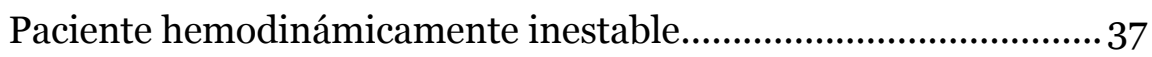

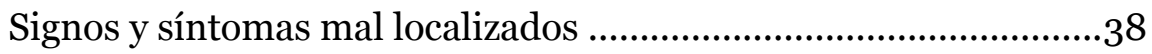

Signos y síntomas localizados en epigastrio ...................................39

Signos y síntomas en el cuadrante izquierdo ..................................43

Conclusión .............................................................................. 51 


\section{INTRODUCCIÓN}

El abdomen agudo es una patología abdominal dolorosa, desarrollado más o menos a corto plazo, de periodicidad reciente y repentina; como principales características posee ataques o exacerbaciones de enfermedades crónicas que requieren evaluación $\mathrm{y}$ tratamiento inmediatos. La característica común de este síndrome es el dolor abdominal, sin embargo, otros signos o síntomas dependen del cuadro que presenten. Entre varias clasificaciones existentes, el abdomen agudo se clasifica como traumático o no traumático y, a su vez, este último se clasifica como falso (razón Verdadero y falso (causas en el abdomen), el cual puede requerir tratamiento médico, ya sea endoscopia o método quirúrgico. Es preciso mencionar que, según su causa, las enfermedades que requieren cirugía se deben a las características de obstructivo, inflamatorio o vascular.

En una investigación sobre pacientes, completado en Guayaquil en 2019 se descubrió que el procedimiento normal 
estaba siendo sometido a una cirugía abdominal aguda, sin embargo, más del 70\% de las causas están relacionadas con enfermedades biliares, apendicitis y hernias de la pared abdominal. Sin investigación profunda todavía el informe sobre el porcentaje de causas inesperadas puede considerarse muy bajo. Aun así, existen cirujanos que tratan a pacientes con abdomen agudo mediante métodos quirúrgicos inexplicables, $\mathrm{y}$ estos deben considerarse, sobre todo en enfermedades insospechadas que están tomando forma.

Se consideró como búsquedas claves Clinical Key y en PubMed, con: "Causa, accidente y grave Abdomen" como términos claves, y 44 artículos publicados en los últimos cinco años. Esta revisión ha identificado la literatura científica y las causas más comunes de etiología desconocida. Asimismo, también se presentó el caso de un paciente abdominal agudo, ante quien se desarrolló un tratamiento quirúrgico complejo. 


\section{Capítulo I: Apendicitis epiploica}

Los apéndices son estructuras grasas con pedículos que se extienden por el colon, los cuales están irrigados por diminutas ramas ubicas lógicamente en los vasos rectos, y existe un gran riesgo de reversión y necrosis, lo cual provoca las manifestaciones clínicas de la subblefaritis. (Apendicitis), este cuadro puede ocurrir en cualquier edad del probable paciente, y el cuadro por lo general se presenta en el sexo masculino. Puede manifestarse como dolor abdominal, principalmente en el cuadrante inferior, porque suele ser el epidídimo más común.

Puede ocurrir en $0,3 \%$ a $1 \%$ de los pacientes sospechoso de apendicitis, de los cuales del $3 \%$ al 7,1\% padecen sospecha de diverticulitis (1). Como señales, un análisis de sangre puede identificar una inflamación, un diagnóstico que el cirujano podría sospechar como Apendicitis o diverticulitis. La imagen de sangre puede mostrar leucocitosis leve y velocidad de sedimentación. La forma esférica (ESR) puede aumentar. Los 
resultados de la muestra, mediante una tomografía computarizada (TC) típica, por ejemplo, pueden presentar una masa de forma ovalada junto al colon con mayor densidad Hay anillos gruesos, transparentes y súper densos alrededor. A veces, un "punto" central de alta densidad puede confirmar el diagnóstico de apendicitis, con estos, puede utilizar tratamiento conservador durante una o dos semanas, una vez que los síntomas presentados y la tomografía realizada mejoran el cuadro enormemente.

\section{Torsión del epiplón}

Menos de 500 casos notificados en todo el mundo sobre la torsión del epiplón, incluso en La tasa de laparotomía en niños con sospecha de apendicitis aguda es del 0,1\% y del 0,4\% en adultos. Realiza una apendicectomía. Como dato más frecuente, se encuentra que hay más de hombres que mujeres con este cuadro, sobre los cincuenta años de vida. Puede ser primaria o secundaria; los cuales están relacionados con aspectos netamente de antecedentes del trauma, como hernias, 
obesidad, quistes, tumores, etc. En lo referente a la necrosis tisular, se debe a la torsión en su eje longitudinal, lo cual termina causando una isquemia (2)

Por lo general, los pacientes reportan fiebre y dolor abdominal, $\mathrm{y}$ ante ello se puede encontrar irritación peritoneal y hemograma durante el ingreso. Puede mostrar leucocitosis, ya que generalmente es diagnosticado, aunque cada vez más, esto se hace durante la cirugía. Aparecen a menudo, y gracias a la aparición de una mejor tecnología Imágenes, el diagnóstico puede ser cuando exista sospecha clínica previa a la cirugía, mediante tomografía computarizada, la cual es el principal estudio complementario.

El tratamiento es quirúrgico y generalmente requiere una resección total, para una recuperación normal suficiente, sin casos reportados de reversión donde reaparece después de la resección segmentaria. 


\section{Enfermedad del divertículo de Meckel}

El divertículo de Merkel $^{1}$ se describió en 1809, el cual corresponde al tubo gastrointestinal duradero, y cuya anomalía congénita es la más común del sistema digestivo. Contiene todas las capas de la pared intestinal, convirtiéndose en un divertículo real. Está localizado en el borde proximal de la válvula del íleon distal La incidencia de ceguera del íleo en los niños es el doble que en las niñas La edad más común es 2 años, aunque el diagnóstico es más común antes de la cirugía en niños, en el caso de los adultos son debido a simulaciones de apendicitis. Excepto el examen físico Leucocitosis, ESR y TC elevadas, puede guiar el diagnóstico.

Las complicaciones más comunes son obstrucción intestinal. En los adultos, ocurren, además, el sangrado intestinal y diverticulitis con o sin perforación. El tratamiento es cirugía,

\footnotetext{
${ }^{1}$ Es una bolsa en la pared de la parte inferior del intestino delgado que está presente al nacer (congénito). El divertículo puede contener tejido similar al del estómago o del páncreas.
} 
aunque generalmente durante la diverticulectomía a veces se requiere una resección intestinal más grande.

\section{Hernias internas}

Las hernias congénitas son más comunes, las cuales pueden representar el $1 \%$ del número total de niños Casos de obstrucción intestinal; los más comunes son Duodenal. Entre los adultos, la causa más común La causa de la obstrucción intestinal es la adherencia de la pared abdominal, la vegetación y la hernia o hernia. Los más comunes son las persianas A través del mesenterio y la membrana superior. Han sido descritos Incluida la hernia de hiato de Winslow.

Hay síntomas crónicos en algunos casos, especialmente dolor abdominal inespecífico y estreñimiento, pero en aproximadamente el 70\% de los casos, el paciente presenta síntomas agudos, o síntomas obstructivos típicos intestinal. Reportado en varias publicaciones hasta el 50\% de la isquemia intestinal presenta casos quirúrgicos, con una mortalidad Del 
20 al 50\% 11. Si tiene una hernia interna congénita es preciso considerar cualquier diagnóstico diferencial a pacientes con abdomen agudo, con o sin antecedentes de cirugía. Los imanes pueden hacer un diagnóstico antes de la cirugía, especialmente en el caso de hernia paraduodenal, pero en la mayoría de los casos, el diagnóstico se realiza durante la cirugía, la cual sería laparoscópica o abierta, como tratamiento seleccionado.

\section{Neoplasias insospechadas}

Este cuadro aparece en pacientes con sospecha de tumores, o manifestaciones clínicas anormales, que pueden manifestarse como signos clínicos de obstrucción en forma crónica o aguda, perforación, respuesta inflamatoria sistémica o cambios hemodinámicos. Suelen ser diagnosticados en pacientes mayores de 60 años. Los tumores pueden dañar los órganos internos, especialmente el hígado o los órganos internos huecos, especialmente los intestinos e incluso el útero. Aunque el tumor que establece como causas primarias benignas del intestino delgado incluye menos del $3 \%$ de todos los tumores 
gastrointestinales, habitualmente asintomático, y se han descrito casos sobre el desarrollo de neurofibromas entéricos. Una de sus complicaciones, como hemorragia intestinal, bloqueo o perforación. (3)

Aunque la metástasis al colon es muy rara, se ha descrito en casos de tumores gástricos primarios, mama, ovario, cuello uterino, riñón, pulmón, próstata y piel. En algunos casos, se presenta el tumor primario de pulmón, el paciente muestra la imagen. En cuanto al abdomen agudo por perforación o metástasis de colon, que estos pacientes pueden también mostrar síntomas de obstrucción intestinal. Se han descrito casos de pacientes con perforación intestinal, donde hay metástasis intestinales conocidas, que ha experimentado Quimioterapia 1.

En estos pacientes, el tratamiento es quirúrgico, debe controlar el sangrado y extirpar el tumor tanto como sea posible. En caso de daño intestinal la posibilidad de hacer esto debe evaluarse por separado, anastomosis, durante la misma operación, o solo 
resección y ostomía, según el estado de infección y la nutrición de cada paciente.

\section{Enfermedad esplénica}

Varias enfermedades esplénicas pueden causar lo que se denomina abdomen agudo, de las cuales las más reconocidas son las siguientes:

\section{Ruptura}

No incluye trauma abdominal La principal causa de ruptura del bazo, la causa más común. Los más comunes incluyen: infecciones (malaria, mononucleosis infecciosa, tuberculosis, hepatitis A, VIH), enfermedad tumoral o sanguínea (linfoma, leucemia, mieloma múltiple, anemia hemolítica, policitemia Vera) y enfermedades degenerativas (amiloidosis), entre ellos. Es más común en hombres y mujeres durante la tercera década de vida, donde esta enfermedad crónica inicial debe ser oportuna si la cirugía no se realiza a tiempo, y esto puede causar la muerte. 


\begin{abstract}
Absceso
Su frecuencia se reduce, pero aún ocurre, especialmente en pacientes con función inmunológica debilitada, o tiene antecedentes de trauma. Se han reportado casos variados como esofágicas secundarias a escleroterapia y después de colangiopancreatografía retrógrada Endoscopio suele ocurrir en hombres jóvenes que necesitan cirugía; solo se puede evaluar en determinadas circunstancias. Elección radiológica drenaje percutáneo Intervencionista.
\end{abstract}

\title{
Torsión
}

Hay informes, especialmente en mujeres entre los treinta y cuarenta años de vida, donde aparece como puerta de bazo larga o delgada propenso a esta enfermedad. Es necesario tratamiento quirúrgico.

\section{Púrpura hepática (peliosis hepatis)}

Esta es una enfermedad rara caracterizada por varios quistes que están cubiertos de sangre y distribuidos por todo el 
parénquima hepático, a pesar de que el hígado es el más comúnmente afectado, esta enfermedad también puede afectar el bazo, la médula ósea, los pulmones y los ganglios linfáticos abdominales están agrandados.

Esta entidad afecta el sistema reticuloendotelial, pero, la causa aún no se ha determinado por completo. Entre Múltiples factores causales son el tratamiento. Efectos farmacológicos (6-mercaptopurina, anabólicos, Azatioprina, esteroides anticonceptivos, danazol, glucocorticoides, tamoxifeno), el curso de la infección (Endocarditis bacteriana, VIH, lepra, pielonefritis, sífilis, tuberculosis), secreción sanguínea anormal (linfoma, enfermedad de Hodgkin, metaplasia medular, enfermedad de Fanconi, macroglobulinemia), tumores (Adenocarcinoma de colon o estómago, cáncer Células hepáticas, cáncer de páncreas, cáncer de próstata, Carcinoma de células renales) y otras causas (trasplante) corazón, hemodiálisis crónica, enfermedad de Crohn, 
Diabetes, artritis reumatoide, lupus eritematoso Alcoholismo sistémico o incluso).

Estos pacientes son generalmente asintomáticos y su diagnóstico frecuentemente se hace de forma incidental en estudios imaginológicos (ecografía, resonancia magnética, gammagrafía o angiografía hepática) o durante la exploración laparoscópica. Clínicamente, el paciente puede presentar hepatomegalia o esplenomegalia, dolor abdominal, masa abdominal palpable o distensión abdominal. En muy pocos casos, se presenta con síntomas relacionados con algunas de sus complicaciones: hipertensión portal, insuficiencia hepática, síndrome hepatorrenal y abdomen agudo por hemoperitoneo debido a la ruptura de una de sus cavidades. Cuando la etiología se relaciona con la administración de medicamentos, esta enfermedad puede resolverse tras su suspensión.

Cuando la causa es infecciosa, la púrpura hepática puede desaparecer después del tratamiento correspondiente, en caso 
de sangrado, el tratamiento puede ser mediante embolia o puede requerirse cirugía.

\section{Hemoperitoneo espontáneo}

Según la literatura científica, hasta el 90\% de los casos Se cree que el sangrado peritoneal es el origen Traumatismo, generalmente una lesión de órganos físicos (Hígado, bazo). La segunda razón más común es origen ginecológico, principalmente por embarazo Rotura ectópica. Sangrado intraabdominal espontáneo Puede ser causado por un aneurisma roto. Tumor sólido congénito (arteria esplénica) roto (Hígado), sangrado de venas varicosas (hipertensión portal) o Trastornos de la coagulación (hemofilia). En algunos

En algunos casos, la peritonitis espontánea es idiopática. Lo sé La proporción de hombres a mujeres es similar, puede suceder a cualquier edad aunque en la mayoría de los casos el diagnóstico puede sospecharse de la consulta del paciente, y en la mayoría de los casos, solo puede hacer esto la forma 
intraoperatoria representa urgencia Debe ser diagnosticado y tratado a tiempo.

\section{Vasculitis}

Dañando arterias de pequeño y mediano calibre, la vasculitis representa la causa subyacente del abdomen agudo. Se manifiestan como dolor abdominal, donde a menudo acompañado de edema de la pared del párpado superior, la función abdominal y renal está alterada. Hasta 42 En algunos casos, los pacientes presentan síntomas del aparato digestivo, que pueden ser la causa según determinadas publicaciones Hasta el 2\% de los casos de isquemia mesentérica. La laparoscopia puede identificar la presencia Isquemia intestinal. Este hallazgo es muy común realizado durante la cirugía en estos pacientes, a menudo necesitan aceptar terapia de hemodiálisis y glucocorticoides. 


\section{Otras causas}

Hay informes de otras causas abdominales inesperadas. Agudo, como gastritis enfisema, perforación ileal Fiebre tifoidea, torsión de estómago, infarto esplénico, enfermedad de xantosarcoma cólico, vólvulo de la vesícula biliar y perforación intestinal espontánea.

\section{Caso clínico}

Se trata de un hombre de 36 años que consultó a los servicios de urgencias del Hospital Central de Policía, con dolor abdominal que evoluciona en cuatro días, localmente, inicialmente a la derecha, luego se extiende a fosa derecha, la fiebre no se cuantifica como Síntomas relacionados en los últimos dos días. Negó tener otros síntomas, este es el primer episodio. no mencionado Antecedentes personales o familiares importantes. En la exploración física, los pacientes con taquicardia presentan irritación peritoneal sistémica. No hay otros hallazgos positivos. Hemograma y Parte de la orina es 
normal. La proteína C reactiva (PCR) es de $49 \mathrm{mg} / \mathrm{L}$ (normalmente hasta $5 \mathrm{mg} / \mathrm{L}$ ) y La ecografía abdominal es normal.

Con un posible diagnóstico de abdomen agudo, la apendicitis, tratada con cirugía abierta o torsión intraoperatoria y necrosis segmentaria omentum, para esta resección de convulsiones, la evolución es buena, ya que el paciente está sano y listo después del alta, y hay suficiente control después de la cirugía, lo cual se toma como evidencia histopatológica de epiplón con infarto hemorrágico Focal y peritonitis. 


\title{
Capítulo II: Métodos de diagnóstico
}

\begin{abstract}
Algunos avances en medicina en las últimas décadas han proporcionado un progreso diagnóstico inicial en la distinción de órganos, o áreas principalmente afectadas, tales métodos pueden clasificarse como no invasivo, incluyendo ecografía, tomografía axial computarizada, resonancia magnética, espiral y tridimensional, etc. 3-7. También existen los que se consideran invasivos, como la punción Bajo la guía de diagnóstico por ultrasonido, laparoscopia o endoscopia o sin guía, en algunos casos, estos métodos se pueden proporcionar y utilizar tratamiento de forma terapéutica.
\end{abstract}

A pesar de ello, las propiedades patológicas y en orden de magnitud, la investigación puede simplemente transferirse al nivel básico o superior del quirófano. Como una tomografía computarizada en espiral o una resonancia magnética o Ecografía tridimensional, teniendo en cuenta las complicaciones abdominales agudas. ¿Está relacionado con el 
tiempo, de modo que Es conveniente que los pacientes realicen una laparotomía exploratoria (cirugía abierta o Endoscopia), desde un diagnóstico incierto hasta un diagnóstico certero con retraso quirúrgico? Por otro lado, es importante recordar que la investigación avanzada nunca reemplazará un buen historial médico el escaneo es bueno.

\section{Cirugía endoscópica}

La cirugía endoscópica de principio a fin durante la década de los 80 y principios de la última década presenta efectos relacionados sobre el tratamiento y el diagnóstico patología abdominal, posteriormente en cada rama de la cirugía. inicial Llamado el método laparoscópico, ahora el concepto integral se llama cirugía endoscópica porque utiliza cada vez más tecnología avanzada Microprocesador, tecnología de cámara Mayor resolución, mejores instrumentos endoscópicos y en última instancia, proporcione mejores calidades de la atención al paciente. 
Ahora que tenemos una laguna más pequeña, podemos ejecutar y se realizan mediante cirugía abierta o convencional. En los primeros días de nuestro tiempo, la investigación y el diagnóstico preciso de la cirugía endoscópica representa sin duda uno de los mayores avances en el campo de la cirugía. Incluso si existen dudas diagnósticas, la cavidad abdominal se puede visualizar directamente sin muestreo ni biopsia. En el caso de trauma y shock severo, que pueden requerir más tiempo y más tiempo de recuperación, la aplicación de este método puede ser limitada.

Hoy en día, este método es una práctica común, ahora en la mayoría de los programas, por tanto, en nuestro país y en el mundo su implementación y desarrollo son y serán cada uno nuevamente es la opción más utilizada. Recientemente, este método está siendo modificado, por ejemplo, el acrónimo inglés método NOTES: (cirugía endoscópica de cavidad natural) se refiere a la cirugía endoscópica a través de un orificio naturales, como el tracto gastrointestinal (estómago, 
duodeno, colon, etc.), tracto urinario y otros órganos de la paciente candidata. Los resultados preliminares son alentadores, tiene un gran potencial y con al comienzo de la cirugía endoscópica, limitaciones que superará la curva el aprendizaje y la experiencia de cirujanos formados en este campo.

Otro ejemplo es la cápsula endoscópica, la que nos proporcionó una serie de imágenes, como hemorragia gastrointestinal y lesiones, se consideran benignos y tumores y otros difícil de diagnosticar y acceder, especialmente en el intestino delgado.

\section{Padecimientos de origen no traumatológico}

Este conjunto de signos y síntomas no es únicamente de la población adulta, existe un gran número de patologías en pediatría y geriatría que se presentan con datos abdominales que requieren atención médica de urgencia como son en los niños la intususcepción intestinal, apendicitis aguda, divertículo de Meckel perforado, etc. y en la población adulta 
mayor casos de cáncer, perforación de víscera hueca (por enfermedad ácido-péptica, salmonella, divertículo de Meckel, etc.), isquemia intestinal, diverticulitis aguda, sangrado de tubo digestivo, etc.

En el embarazo y como cualquier paciente, puede cursar con alguna patología de urgencia abdominal o ginecológica, ejemplos frecuentes son el embarazo ectópico en sus primeras semanas de gestación apendicitis y colecistitis agudas en el transcurso del embarazo entre otras que requieren un tratamiento quirúrgico de urgencia.

\section{Fisiopatología}

La patogenia del abdomen agudo y las características y el diagnóstico del dolor abdominal deben basarse en la causa de la enfermedad. Hay tres tipos de dolor asociados con el abdomen agudo:

1) Dolor visceral, causado por distensión abdominal, calambres, isquemia e irritación. Manifestado como profundo, 
difuso y Mala posición, en casos severos, irá acompañada de parestesias, hiperalgesia y rigidez muscular involuntaria.

2) Dolor corporal, síntoma más común agudo y localizado desde el peritoneo Lóbulo parietal, raíces mesentéricas y transversales del diafragma, y

3) se refieren al dolor, relacionado con el sitio del proceso original y que se manifiesta en el trayecto de la extremidad superior trasera o extremidad superior trasera Transmisión inflamatoria o infecciosa.

El proceso de inflamación e infección es La razón principal, por lo que debe recordarse. La invasión bacteriana produce dos tipos de reacciones: una local con adecuada defensa antibacteriana y otra con desempeño hemodinámico, metabólico y neuroendocrino. de La lesión peritoneal estimula la liberación de sustancias. Mayor vasoactividad y permeabilidad peritoneal, así como la participación de diferentes mediadores, y a las pocas horas, Una fuerte 
respuesta celular y humoral a nivel del sistema puede conducir a una disfunción o falla orgánica y, finalmente, a la muerte.

\section{Cuadro clínico}

Interrogar sobre el historial médico de un paciente es el análisis exhaustivo de las características del dolor y la detección de antecedentes médicos relacionados son importante. Del mismo modo, los síntomas acompañantes como fiebre y vómitos están relacionados con la causa del abdomen agudo.

\section{Diagnóstico}

El elemento básico para analizar estos cuadros es distinguir imágenes sobre el abdomen agudo causado por dolor abdominal, razonar y luego determinar si el proceso, tratamiento farmacológico o quirúrgico. Otros elementos, por ejemplo, para reacciones sistémicas, se deben detectar y considerar factores de riesgo (obesidad, embarazo, inmunidad debilitada, ancianos, etc.), especialmente en casos atípicos. 
Aplicaciones de investigación de laboratorio y gabinete fue instruido para detectar patología intraperitoneal, esencialmente un procedimiento quirúrgico, desde el más básico. El más complejo y potencialmente intrusivo Invasiva (por ejemplo, lavado peritoneal, laparoscopia diagnóstica). La investigación básica de laboratorio incluye: biología sanguínea, alquimia y química sanguínea. Reste tres elementos, tiempo de coagulación, análisis de orina y mujeres en edad fértil. Prueba inmunológica de embarazo; imágenes de la parte superior del abdomen: pruebas de amilasa, lipasa y función hepática.

La investigación del gabinete se debe utilizar tradicionalmente con radiografías de tórax y una simple radiografía del abdomen o en algunos casos, una forma rápida para algunas personas servicios de emergencia, especialmente con sufre trauma. La ecografía de rutina, transvaginal o endoscópica y la tomografía computarizada son muy útiles cuando no se utilizan retrasan 
mucho el tratamiento quirúrgico, y finalmente realizaron laparoscopia.

\section{Diagnóstico diferencial}

Otro elemento básico es distinguir entre otras patologías que provocan el abdomen agudo o lo siguen, para que puedas visualizar fácilmente la patología principal asociada a cada abdomen. Área abdominal: Abdomen superior derecho: pancreatitis aguda, hepatitis aguda, hepatomegalia congestiva aguda, neumonía pleural reactiva, pielonefritis aguda, angina de pecho, absceso hepático.

Cuadrante superior izquierdo: pancreatitis aguda, aneurisma aórtico, colitis aguda, pielonefritis, neumonía, infarto agudo de miocardio. Alrededor del ombligo: obstrucción intestinal, pancreatitis. Diverticulitis aguda.

Cuadrante inferior derecho: Enfermedad inflamatoria pélvica, salpingitis aguda, quiste ovárico complicado, 
embarazo ectópico roto, adenitis mesentérica, diverticulitis Meckel, cálculos ureterales, ileítis terminal.

Cuadrante Abajo a la izquierda: diverticulitis, enfermedad inflamatoria pélvica, salpingitis aguda, quiste Ovarios complejos, embarazo ectópico roto, colon descendente, tumores o cuerpos extraños en cálculos ureterales. 


\section{Capítulo III:}

\section{Guía para el manejo de abdomen agudo}

El diagnóstico y tratamiento de pacientes con dolor y sintomatología de abdomen agudo es uno de los mayores desafíos para médicos generales y cirujanos. Este capítulo tiene como objetivo proporcionar un resumen de los aspectos más importantes para tomar en cuenta al comenzar a evaluar al paciente que tiene esta patología, a continuación, se detalla:

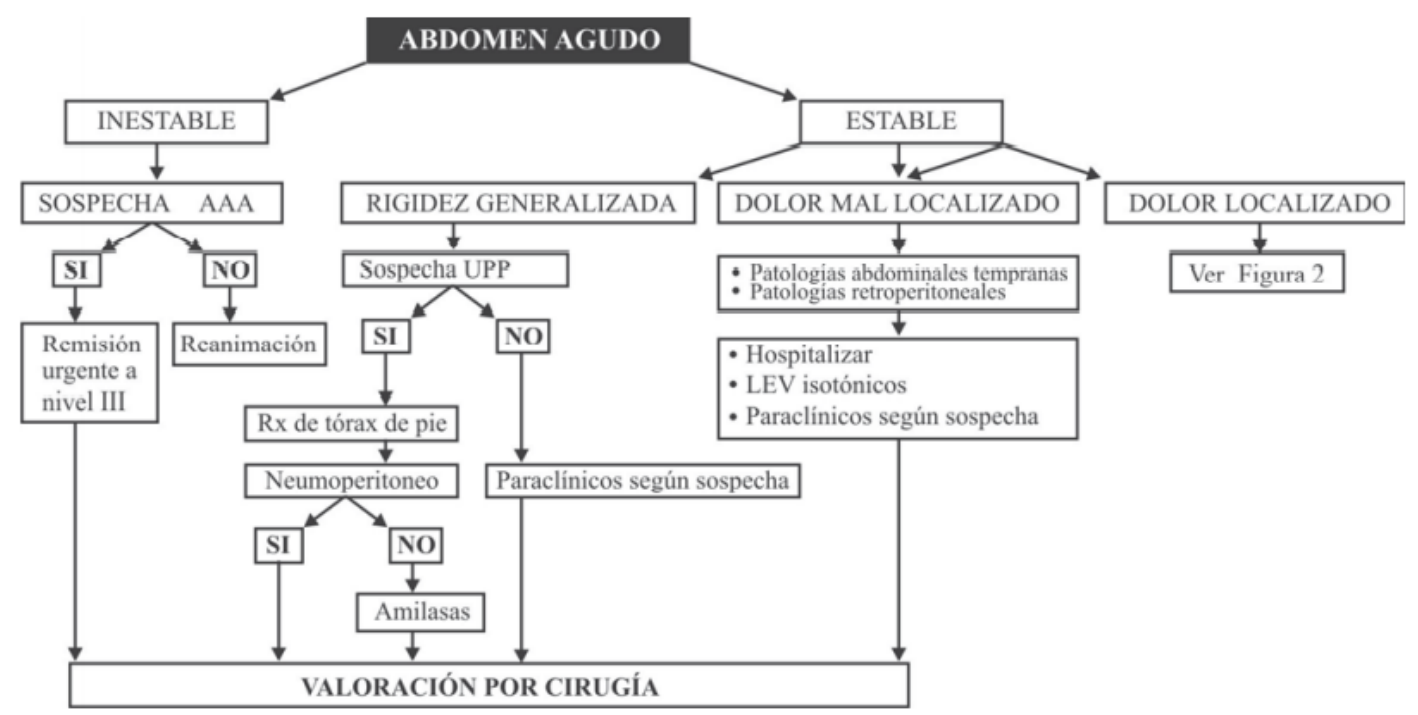

Figura 1: Flujograma de manejo de Abdomen Agudo 


\section{Clasificación}

1. Síndromes Peritonítico o Inflamatorio Visceral

2. Síndrome Oclusivo

3. Síndrome Hemorrágico

4. Síndrome Mixto o Indefinido

\section{Enfoque del abdomen agudo}

Para hacer un correcto diagnóstico es fundamental historial médico completo y excelente examen físico como foco del abdomen según la historia clínica, la aguda es del 80\%, exploración física y 20\% de ayudas diagnósticas. La atención debe centrarse en el dolor, que es un síntoma. La investigación principal y básica del abdomen agudo. La causa de la operación precede a otros síntomas, como vómitos, fiebre, náuseas, reversión del dolor Médico.

En cuanto al dolor, cabe preguntarse: apariencia, Ubicación, iluminación, características, intensidad y síntomas 
relacionados. Pregunte el historial médico del paciente puede determinar si esto pertenece a la categoría de paciente Especial, porque estos deben ser observados y manejados diferente de la población general.

El llamado paciente especial tiene las siguientes características:

-Pacientes mayores de 60 años

-Mujeres embarazadas

-Pacientes obesos

-Pacientes inmunodeprimidos

-Pacientes envenenados

$\cdot$ Niños

-Pacientes con enfermedades sistémicas, como Insuficiencia renal crónica (IRC), cirrosis hepática, tiene una enfermedad de 
la sangre o recibir anticoagulantes, diabetes, tumor previo, sensación de deterioro médula.

- Pacientes con sepsis grave o Fallo multiorgánico

Clasificación de los pacientes con dolor abdominal agudo no traumático según severidad y conducta inicial

\section{ESTADIO o}

A. Paciente previamente sano con dolor abdominal agudo cuyo diagnóstico clínico corresponde a una patología leve de manejo médico.

\section{Conducta}

- No requiere hospitalización

- No requiere observación

- No valoración por especialista 
B. Pacientes previamente sanos con dolor abdominal agudo, en este caso sin otros síntomas obvios Evaluación o descubrimiento rápido de procesos patológicos Intraabdominal.

\section{Conducta}

- $\quad$ No es necesario ser hospitalizado

- $\quad$ Requiere observación

\section{Estadio I}

A. Pacientes con dolor abdominal agudo, donde los hallazgos clínicos sugieren la condición en la cavidad abdominal, pero el diagnóstico no está claro. Actualmente, estos pacientes no tienen factores de riesgo y no pertenecen a un grupo especial de pacientes más delicados.

-Necesita ser hospitalizado 
•Suspensión oral

- Repetir el examen clínico

-Solicitud sospechosa de análisis de laboratorio clínica

-No tome analgésicos

-No le dé antibióticos

•Evaluación del cirujano

\section{Estadio II}

A. Pacientes con hallazgos clínicos muy sugestivos Requiere examen patológico intraabdominal agudo cirugía o medicación para solucionar su problema.

B. Pacientes pertenecientes a las siguientes categorías de especiales

C. Pacientes que necesitan dolor abdominal agudo otras pruebas de diagnóstico para evaluar su dolor abdominal. 


\section{Conducta}

El primer paso es determinar si el paciente encontrado hemodinámicamente estable o inestable.

\section{Paciente hemodinámicamente inestable}

Si el paciente tiene antecedentes conocidos de aneurisma. Aorta abdominal o dolor y otros síntomas. Espalda, palidez, presión arterial baja y masa abdominal pulsante debe sospechar un aneurisma abdominal roto $\mathrm{y}$ debe Vaya inmediatamente al segundo nivel de salud. Si se descarta la posibilidad de forma satisfactoria después de la ruptura de un aneurisma abdominal, necesita reanimación. Y pídale al cirujano que evalúe.

\section{Paciente hemodinámicamente estable}

En estos pacientes, se debe determinar si existe rigidez abdomen, si el hallazgo es positivo solicitar Una radiografía de tórax de pie que permite al cirujano Se puede evaluar el neumoperitoneo. Si radiografía estar de pie es normal, luego se 
hará una solicitud Amilasa. Pacientes hemodinámicos método estable sin rigidez abdominal según la ubicación de los síntomas y signos.

\section{Signos y síntomas mal localizados}

Sugieren cualquiera de las patologías intrabdominales en su estadio inicial o un proceso retroperitoneal. En este tipo de pacientes se deben tener en cuenta las siguientes patologías:

- Aneurisma aórtico abdominal

- Enfermedad inflamatoria intestinal

- Obstrucción intestinal temprana

- Isquemia mesentérica

- Apendicitis en estadio inicial

- Enteritis

- Pancreatitis 
- Enfermedades metabólicas

\section{Conducta}

- Hospitalizar

- Suspender vía oral

- Colocar líquidos endovenosos isotónicos

- Solicitar paraclínicos de acuerdo con la sospecha clínica

- Requiere valoración por especialista

\section{Signos y síntomas localizados en epigastrio}

En el paciente con signos y síntomas localizados en epigastrio se debe pensar en:

- Enfermedad acidopéptica

- Esofagitis

- Patología biliar 
- Pancreatitis

- Isquemia miocárdica

- Otras

\section{Conducta}

- Hospitalizar

- Suspender vía oral

- Colocar líquidos endovenosos isotónicos

- Aplicar dosis de anti H2

- Si hay sospecha más factores de riesgo de evento

coronario agudo, entonces solicitar ECG

- Si el dolor compromete el hemiabdomen superior y está asociado a vómito intenso, entonces sospechar

pancreatitis y solicitar amilasas 
- Requiere valoración por especialista

Signos y síntomas localizados en cuadrante superior derecho

En estos pacientes se debe pensar en las siguientes patologías:

- Patología biliar

- Hepatitis

- Enfermedad acidopéptica

- Patología pulmonar

- Patología de origen urológico

- Isquemia miocárdica

- Alteraciones musculoesqueléticas

- Absceso hepático

- Herpes Zóster 
- Apendicitis

- Síndrome de Budd-Chiari

\section{Conducta}

- Hospitalizar. Admisión en AIM hasta definir diagnóstico

- Suspender la vía oral

- Colocar líquidos endovenosos isotónicos

- Aplicar una dosis de antiH2, de antiespasmódico y analgésico

- Valoración por especialista

- Si hay alta sospecha de patología biliar solicitar ecografía de hígado

- Si hay sospecha de patología urinaria solicitar parcial de orina

- Si hay sintomatología del tracto respiratorio solicitar radiografía de tórax 


\section{Signos y síntomas en el cuadrante izquierdo}

En esta posición, muestra síntomas sin trauma. Lo primero que se Los pacientes que experimentan dolor deben considerar el abdomen no traumático es un desastre en esta posición. Vasos sanguíneos, como aneurisma o aneurisma aórtico abdominal arteria esplénica, lesiones relacionadas con el bazo Infarto esplénico, esplenomegalia y daño al colon. Otras razones para considerar son:

- Patología urológica

- Pancreatitis

- Isquemia miocárdica

- Patología pulmonar

- Enfermedad acidopéptica

- Pericarditis

- Herpes Zóster 
- Fracturas costales

- Absceso subdiafrágmatico

\section{Conducta}

- Hospitalización. Ingrese AIM hasta la definición diagnóstico

- Suspender la vía oral

- Coloque líquido intravenoso isotónico

- Tome una dosis de anti-H2, Antiespasmódico y analgésico

- Evaluación experta

- Si se sospecha mucho de patología biliar, solicite ecografía hepatobiliar

- Si se sospecha patología del tracto urinario, pregunte orina parcial

- Si tiene síntomas respiratorios, pregunte radiografía de pecho 


\section{Signos y síntomas localizados en el cuadrante inferior derecho}

Cuando el dolor está en la parte superior del abdomen, lo más importante es considerar el género del paciente, ya que fue diagnosticado por el mayor número de mujeres diagnosticadas. La patología local más común, en este cuadrante, son:

- Apendicitis

- Diverticulitis

- Patología urológica

- Hematoma de pared

- Absceso del Psoas

- Herpes Zóster

- Adenitis mesentérica

- Aneurisma aorta abdominal 
- Enteritis

- Aneurisma de la arteria iliaca

- Hernia de disco

En las pacientes mujeres sospechar, además:

- Enfermedad pélvica inflamatoria

- Quiste torcido de ovario

- Embarazo ectópico

- Mittelschmerz

- Absceso ovárico

- Endometriosis

\section{Conducta}

- Hospitalizar. Admisión en AIM hasta definir diagnóstico 
- Suspender la vía oral

- Colocar líquidos endovenosos

- Valoración por especialista

- No aplicar analgésicos

- No aplicar antibióticos

- Solicitar paraclínicos de acuerdo con la sospecha clínica

Signos y síntomas localizados en el cuadrante inferior izquierdo

Las patologías para considerar son:

- Diverticulitis

- Absceso del Psoas

- Absceso diverticular

- Enfermedad de Crohn 
- Neoplasia perforada

- Hematoma de pared

- Obstrucción intestinal

- Patología urológica

- Colitis

- Herpes Zóster

- Aneurisma aorta abdominal

- Aneurisma arteria ilíaca

- Hernia de disco

- Y en las mujeres sospechar además las patologías mencionadas en el cuadrante inferior izquierdo

\section{Conducta:}

- Hospitalizar. Admisión en AIM hasta definir diagnóstico 
- Suspender vía oral

- Colocar líquidos endovenosos isotónicos

- Solicitar paraclínicos de acuerdo con la sospecha clínica

- No dar analgésicos

- No dar antibióticos

- Valoración por especialista

\section{Notas generales}

- Todas las pacientes mujeres con síntomas y signos, ubicado en el cuadrante inferior del abdomen, es necesario un examen vaginal obligatorio.

- A todos los pacientes derivados de otra institución nivel diagnóstico y nivel de atención dolorosa evaluación de cirugía abdominal a pedido.

- El cirujano es quien posee una mayor perspectiva de diagnóstico de abdomen agudo, quién es responsable en la 
mayoría de los casos del posible tratamiento, por lo tanto, su evaluación no debe llegar tarde.

- En personas llamadas abdomen especial Sharp se comporta como una entidad más compleja.

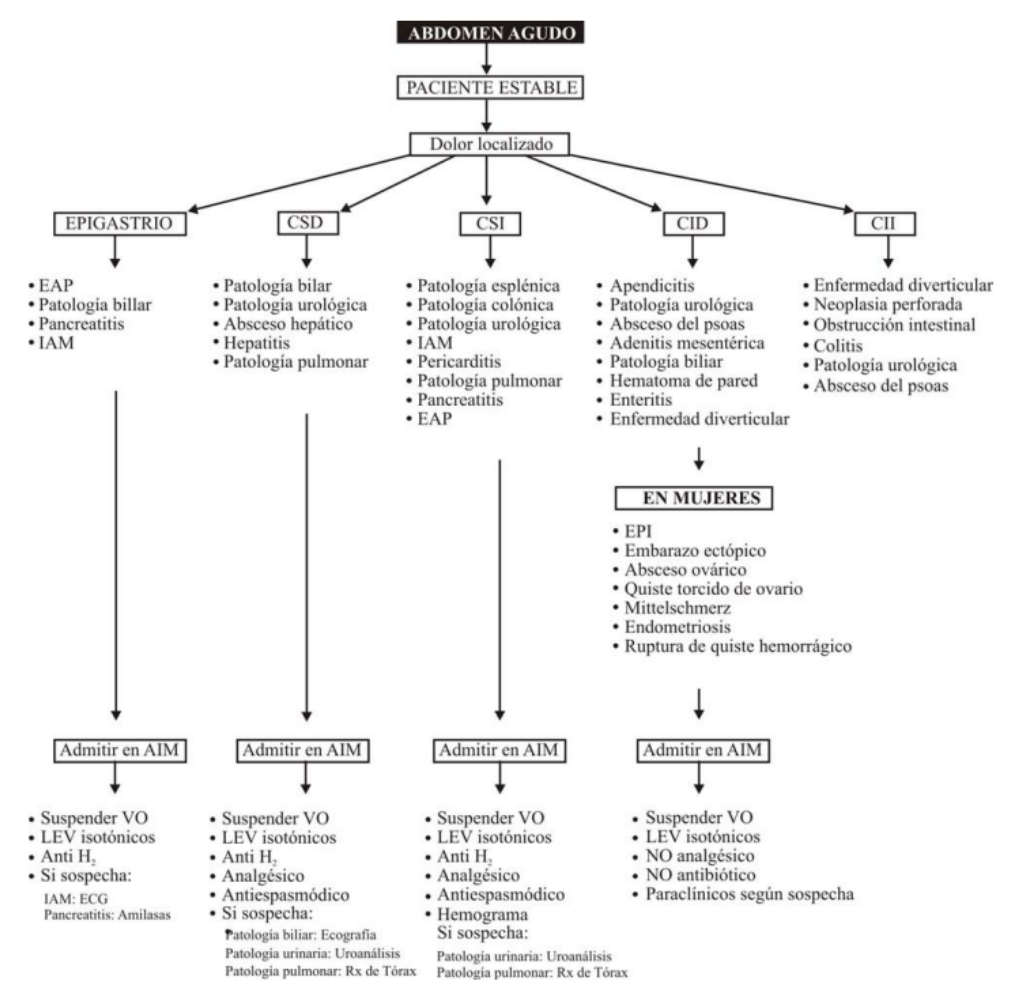

Figura 2: Flujograma de manejo para paciente con Abdomen Agudo y dolor localizado 


\section{Conclusión}

Se llevó a cabo una revisión de la literatura identificando las principales causas inesperadas de abdomen agudo, entre las cuales se encontraron enfermedades de tipo inflamatorio (apendicitis epiploica, torsión del epiplón, compromiso del divertículo de Meckel), obstructivo (lesiones neoplásicas, hernias internas) y vascular (púrpura hepática, ruptura esplénica, hemoperitoneo espontaneo, vasculitis). Consideramos que estas enfermedades deben ser tenidas en cuenta en casos de diagnóstico no claro de abdomen agudo, ya que pueden ser un hallazgo intraoperatorio inesperado. Se presenta un paciente tratado en el Hospital Central de la Policía con diagnóstico de abdomen agudo por probable apendicitis; se practicó una laparotomía exploratoria con hallazgo de torsión segmentaria del epiplón, el cual fue resecado, con una evolución satisfactoria del paciente.

En cuanto al manejo de pacientes con abdomen agudo, es importante que sea rápido $\mathrm{y}$ eficiente, $\mathrm{y}$ requiere un 
tratamiento multidisciplinario, que dependerá de la gravedad de la afección, por ejemplo, la necesidad de apoyo al paciente. Unidad de cuidados intensivos, estable Hemodinámica y manejo antes y después de la cirugía. Gran parte de los casos poco después de la cirugía, camino crítico para seguir para este tipo de imagen, muestra la patología aguda, por ello hay que priorizar la gestión y la penetración vía aérea, adecuada circulación y perfusión tisular. Con una investigación de laboratorio completa se puede definir el gabinete en base a la historia clínica y posible diagnóstico y tratamiento del examen.

Este algoritmo representa el manejo básico en todo paciente que se recibe en un servicio de trauma o de urgencias médicoquirúrgicas, priorizando el $\mathrm{ABC}$ de la evaluación primaria y en caso necesario estabilización del estado de choque de acuerdo con cada paciente en particular. 


\section{REFERENCIAS}

1. Vriesman V, Lohle P, Coerkamp E, Puylaert J. Infarction of omentum and epiploic appendage: Diagnosis, epidemiology and natural history. Eur Radiol. 1999;9:1886-92

2. Occhionorelli S, Zese M, Cappellari L, Stano R, Vásquez G. Acute abdomen due to primary omental torsion and infarction. Case Rep Surg. 2014;2014:208382. 30 de agosto de 2016: Disponible en; http://dx.doi.org/10.1155/2014/208382

3. Kumar S, Khanna S, Roy A, Gupta SK. An unusual cause of hemoperitoneum: Case report with review of literature. Int J Surg Case Rep. 2015;12:120-2. 


\section{Descubre tu próxima lectura}

Si quieres formar parte de nuestra comunidad, regístrate en https://www.grupocompas.org/suscribirse y recibirás recomendaciones y capacitación
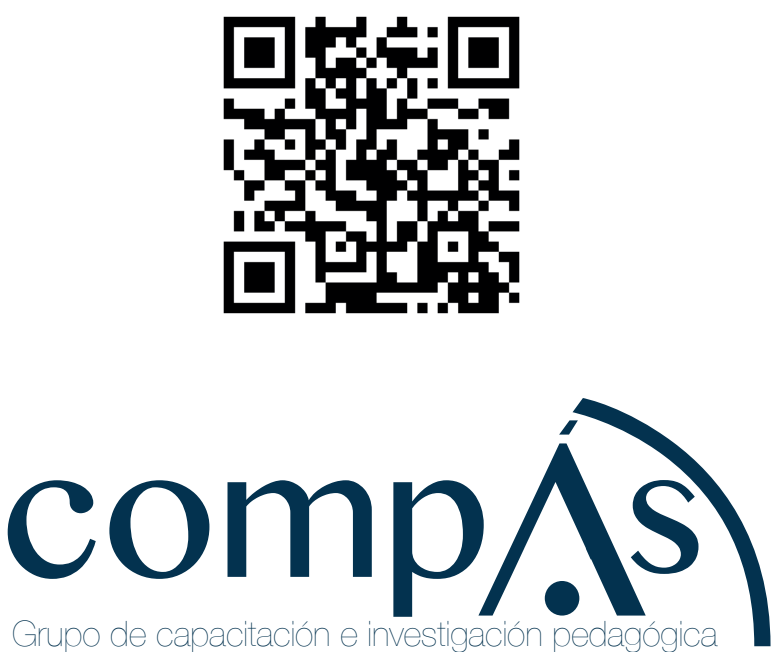

\%

compasacademico@icloud.com 


\section{comp/s}

$5 \bigcirc$ @ @

compasacademico@icloud.com 


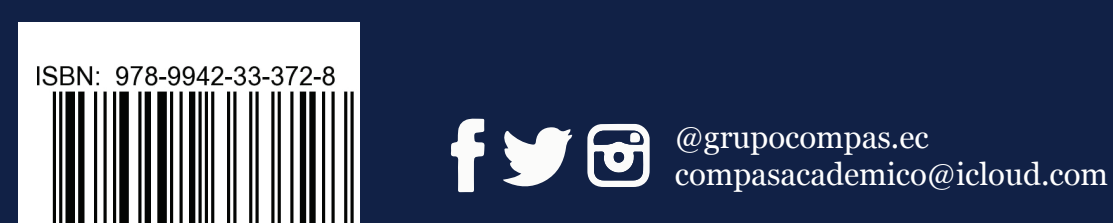

comp/s) 